\title{
Notes on the vocalizations of Blood-breasted Flowerpecker (Dicaeum sanguinolentum)
}

\section{Peter Boesman}

In the following we briefly analyze and compare voice of the different races of Bloodbreasted Flowerpecker (Dicaeum sanguinolentum). We also try to quantify the extent of any vocal differences using the criteria proposed by Tobias et al. (2010), as a support for taxonomic review. We have made use of sound recordings available on-line from Xeno Canto (XC) and Avian Vocalization Center (AVoCet).

An overview of vocabulary per race, illustrated with sonograms:

sanguinolentum (Sumatra (Lampung, two records), Java and Bali).
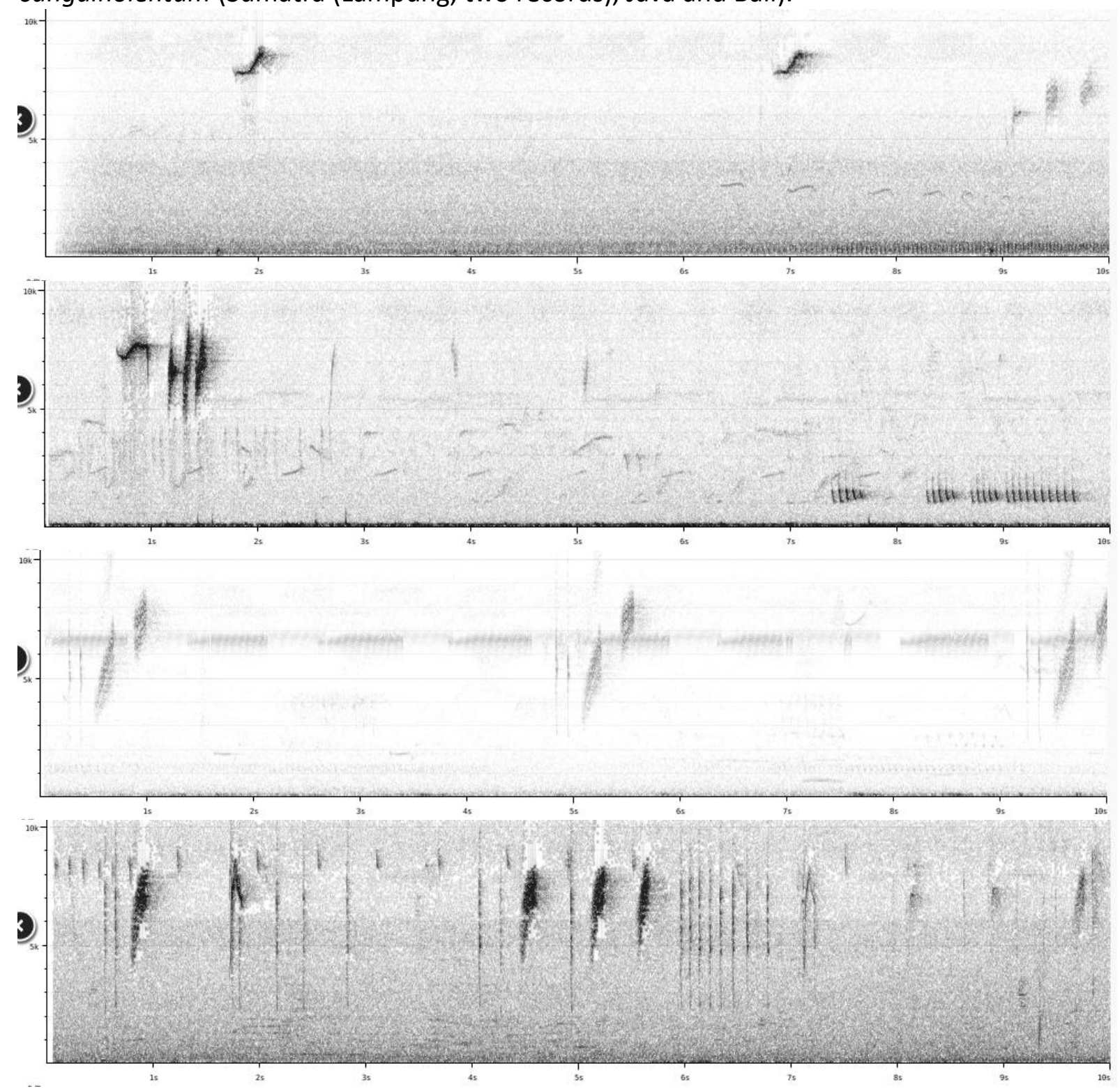


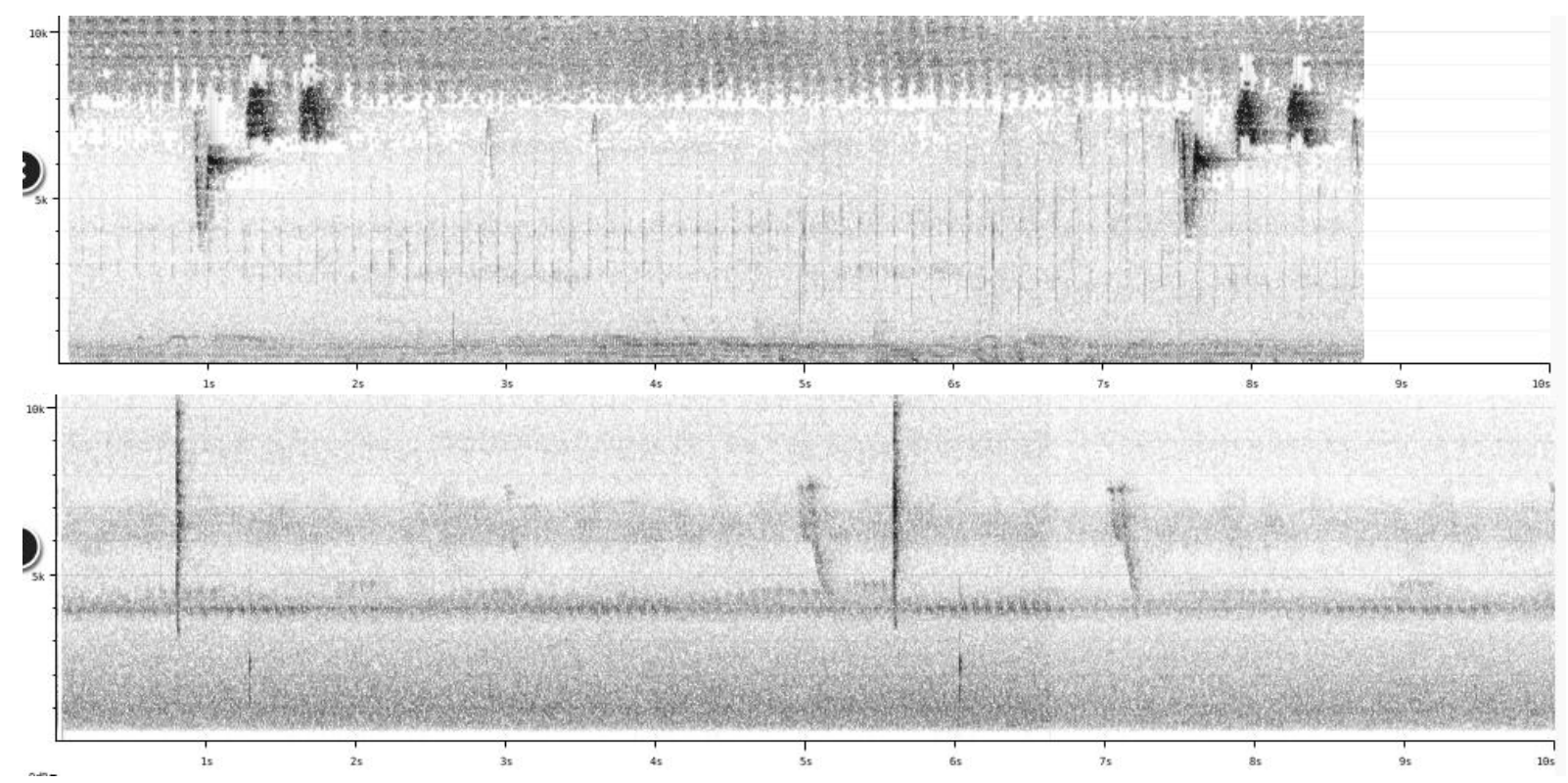

wilhelminae (Sumba, in Lesser Sundas).
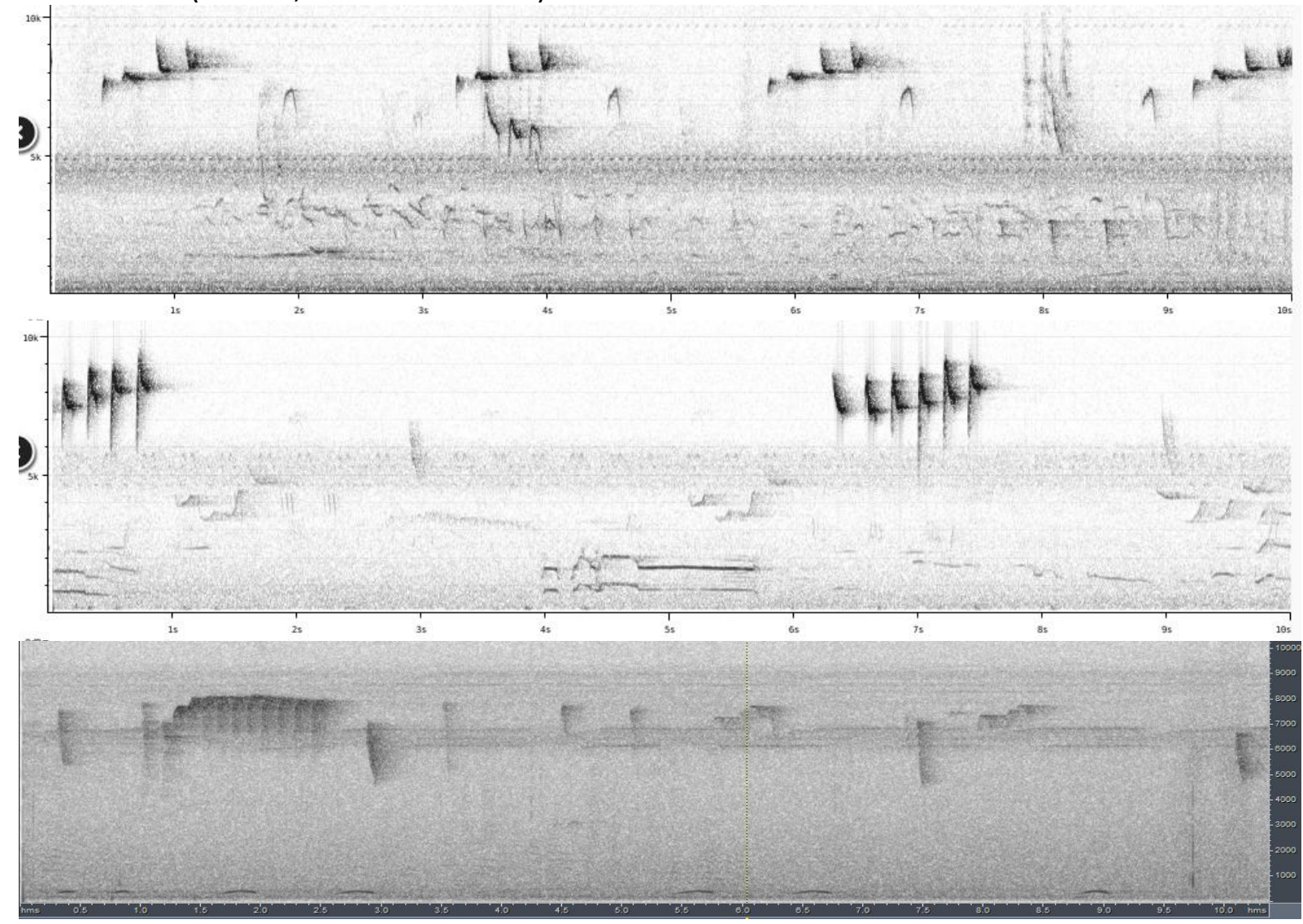

rhodopygiale (Flores).

No recordings available

hanieli (Timor).

No reliable recordings available (There is a single recording from Alor (without visual ID), which would be a range extension (?)) 

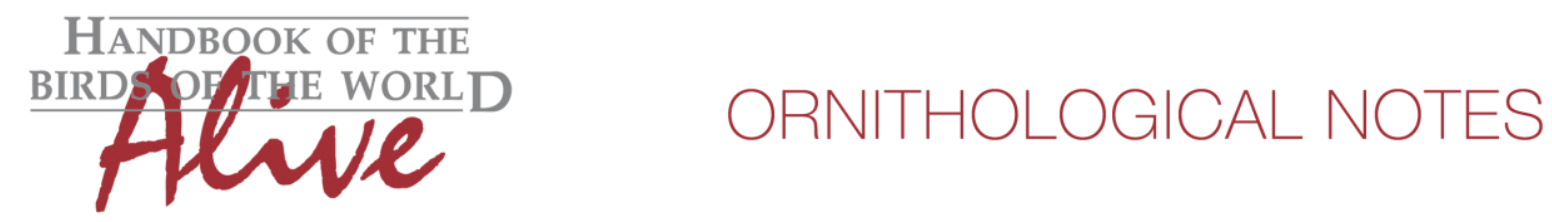

Vocabulary of sanguinolentum and wilhelminae seems to be quite different.

The former uses mainly high-pitched buzzy notes, a thin rising 'seee' and short "chick" notes.

The latter apparently mainly utters series of high-pitched whistles and short "chick" notes.

HBW Alive (Cheke et al. 2016) mentions "various sharp, high-pitched clicks; hard, sharp, buzzing double note. Song, lasting 1-2 seconds, a rather jerky series of 4-5 thin, very-highpitched but sweet notes". It is not clear whether this description is a combination of vocalizations of both taxa or not, but based on the above evidence it would seem so. In this case, we would have to assume that the buzzy notes and the note-series are homologous vocalizations for the two taxa in order to score: lower min. freq. of buzzy notes in sanguinolentum (score 2-3) and higher number of notes in note series for wilhelminae (score 2-3). Obviously, a lot of assumptions are made here, and these are rather preliminary indications of vocal difference, in absence of a clear understanding of vocal repertoire of both groups.

This note was finalized on 25th April 2016, using sound recordings available on-line at that moment. We would like to thank in particular the sound recordists who placed their recordings for this species on XC and AVoCet: Paulo Alves, Bruno Durand, Frank Lambert, Mike Nelson, Pamela Rasmussen, Brendan Sloan, Colin Trainor, Bas van Balen and Filip Verbelen.

\section{References}

Cheke, R., Mann, C. \& de Juana, E. (2016). Blood-breasted Flowerpecker (Dicaeum sanguinolentum). In: del Hoyo, J., Elliott, A., Sargatal, J., Christie, D.A. \& de Juana, E. (eds.). Handbook of the Birds of the World Alive. Lynx Edicions, Barcelona. (retrieved from http://www.hbw.com/node/60152 on 25 April 2016).

Tobias, J.A., Seddon, N., Spottiswoode, C.N., Pilgrim, J.D., Fishpool, L.D.C. \& Collar, N.J. (2010). Quantitative criteria for species delimitation. Ibis 152(4): 724-746.

\section{Recommended citation}

Boesman, P. (2016). Notes on the vocalizations of Blood-breasted Flowerpecker (Dicaeum sanguinolentum). HBW Alive Ornithological Note 335. In: Handbook of the Birds of the World Alive. Lynx Edicions, Barcelona. (retrieved from http://www.hbw.com/node/1252794 on 25 October 2016). 